\title{
Ciências da saúde na TV brasileira
}

\section{Health sciences on Brazilian TV}

\section{Ciencias de la salud en la TV brasileña}

\author{
Vanessa Brasil de Carvalho | vanessabrasilcarvalho@gmail.com \\ Universidade Federal do Rio de Janeiro, Programa de Educação, Gestão e Difusão em Biociências, Química Biológica. \\ Rio de Janeiro, RJ, Brasil.
}

Luisa Massarani | luisa.massarani4@gmail.com

Fundação Oswaldo Cruz, Museu da Vida, Núcleo de Estudos da Divulgação Científica. Rio de Janeiro, RJ, Brasil.

\section{Resumo}

Neste artigo, apresentamos resultados de nosso estudo sobre a veiculação de assuntos científicos relacionados à saúde nas duas principais emissoras da televisão brasileira: TV Globo e TV Record. Analisamos a sua programação diária ao longo de duas semanas construídas referentes a seis meses de 2013, totalizando 672 horas. Observamos que presença dessa temática é reduzida $(2,7 \%)$ e os aspectos científicos aparecem de forma secundária. A publicidade se destacou entre as demais categorias televisivas, o que contribuiu para uma abordagem positiva da ciência. Embora a figura do cientista tenha sido rara, a linguagem científica foi amplamente utilizada como forma de conferir legitimidade às programações. Tal resultado evidencia que a ciência possui um caráter social importante de conferir credibilidade a diversos tipos de informação - fato que se torna mais relevante quando se considera que esse meio de comunicação é o mais presente nos lares brasileiros e possui grande importância cultural no país.

Palavras-chave: Cobertura sobre ciência; Cobertura sobre saúde; Publicidade; Análise de conteúdo; Televisão; TV Globo; TV Record.

\begin{abstract}
In this article, we present the results of a study on the broadcasting of scientific issues related to health on two main channels of Brazilian TV: TV Globo and TV Record. We analyzed daily its programmes over two constructed weeks, which were representative of six months in 2013, totalizing 672 hours. We observed that the presence of health sciences is low (2.7\%) and the scientific aspects appeared in a secondary manner. The advertisement was the most common TV category, contributing to a positive approach of science. Although the scientists has not appeared frequently, the scientific language was widely used as a way of legitimating the TV programmes. This result demonstrates that science is socially important, providing credibility to different kinds of information - a fact that becomes more relevant when one considers that TV is the most present mass media communication in Brazilian homes and it has great cultural importance in Brazil.
\end{abstract}

Keywords: Media coverage of science; Coverage of health; Advertisements; Content analysis; Television; Globo TV; Record TV. 


\section{Resumen}

En este artículo, presentamos los resultados de nuestro estudio sobre la veiculación de temas científicos relacionados a la salud en las dos principales estaciones de la televisión brasileña: TV Globo y TV Record. Analisamos su programación diaria durante dos semanas construidas, representantivas de seis meses de 2013 - un total de 672 horas. La presencia de las ciencias de la salud fue baja (2,7\%) y los aspectos científicos apareceran de forma secundaria. La publicidad se destacó entre las otras categorías televisivas, lo que contribuyó para un enfoque positivo de la ciencia. Aunque la imagen de científicos haya sido poco presente, el lenguaje científico fue ampliamente utilizado para dar legitimidad a las informaciones televisivas. Este resultado evidencia que la ciencia tiene un carácter social importante de conferir credibilidad a diversos tipos de informaciones - un hecho que se hace aún más relevante cuando se tiene en cuenta que la TV es el medio de comunicación más presente en los hogares brasileños y tiene gran importancia cultural en el país.

Palabras clave: Cobertura de la ciencia; Cobertura de la salud; Publicidad; Análisis de contenido; Televisión; TV Globo; TV Record.

\section{Contribuição dos autores:}

Concepção e desenho do estudo: Vanessa Brasil de Carvalho e Luisa Massarani

Aquisição, análise ou interpretação dos dados: Vanessa Brasil de Carvalho e Luisa Massarani

Redação do manuscrito: Vanessa Brasil de Carvalho e Luisa Massarani

Revisão crítica do conteúdo intelectual: Vanessa Brasil de Carvalho e Luisa Massarani

Declaração de conflito de interesses: Não há conflitos de interesse.

Fontes de financiamentos: CNPq, FAPERJ e CAPES

Considerações éticas: Não há

Histórico do artigo: Submetido: 20.dez.2015 | Aceito: 08.maio.2016 | Publicado: 30.jun.2016. 


\section{Introdução}

Estudos têm mostrado uma relação estreita entre temas de ciência e saúde nos meios de comunicação de massa. Einsiedel ${ }^{1}$, por exemplo, analisou como as questões científicas eram tratadas nos principais jornais impressos diários do Canadá e verificou que, embora a ciência tenha um espaço reduzido em relação a outros tópicos midiáticos, os assuntos da medicina foram frequentes. Göpfert ${ }^{2}$ identificou a mesma predominância de temáticas de saúde em programas com abordagens científicas veiculados nas TVs britânica e alemã.

Mais recentemente, Léon ${ }^{3}$ constatou que as questões de saúde foram as mais recorrentes na cobertura televisiva sobre ciência em cinco países europeus. Na América Latina, Almeida e colaboradores ${ }^{4}$ analisaram as notícias publicadas em editorias de ciência em doze jornais impressos de nove países da região, observando que os assuntos sobre saúde foram predominantes em sete desses diários. A mesma tendência foi observada por outras pesquisas em países latino-americanos, como Brasil ${ }^{5,6}$, Colômbia ${ }^{7}$ e Costa Rica $^{8}$.

Segundo Léon ${ }^{3}$, notícias sobre saúde ganham atenção do público porque podem ser transpostas para a realidade dessas pessoas com mais facilidade do que as notícias sobre outros campos da ciência. De acordo com Epstein", a medicina é uma "arena” mais permeável ao debate público em razão da relação direta com o cotidiano.

No Brasil, a última enquete sobre percepção pública da ciência ${ }^{10}$ mostrou que esta e a medicina são áreas de grande interesse: $78 \%$ dos entrevistados afirmaram ter interesse ou muito interesse em relação aos assuntos de medicina e saúde; 61\% expressaram ter interesse sobre questões da ciência \& tecnologia (C\&T). Além disso, 78,1\% das pessoas entrevistadas declararam que consideram ser necessário aumentar os investimentos em C\&T.

Nosso estudo analisa a cobertura televisiva de temas das ciências da saúde no Brasil. Outros pesquisadores já analisaram a pesquisa em saúde na TV, mas, em geral, os estudos incidem sobre um programa ou gêneros específicos. Como exemplo, podemos citar as pesquisas sobre os telejornais Jornal Nacional, Jornal da Record e Repórter Brasil ${ }^{6,11,12}$, o programa de variedades Fantástico da TV Globo ${ }^{13-15}$, as telenovelas, da TV Globo, Barriga de Aluguel e O Clone ${ }^{16,17}$ e o programa de divulgação científica Globo Ciência ${ }^{18,19}$.

O diferencial de nosso estudoi é o fato de analisarmos as diversas categorias televisivas incluídas na programação diária, desde propagandas até novelas, de programas de auditório a programas educativos. Selecionamos a TV como objeto de estudo pelo fato desse meio de comunicação de massa estar presente em $97,2 \%$ dos domicílios brasileiros ${ }^{20}$. Em particular, buscamos contribuir com as reflexões acerca da representação das ciências da saúde nas diferentes categorias televisivas nas duas principais emissoras de TV aberta do Brasil, TV Globo e TV Record, evidenciando os temas mais frequentes, as características marcantes e as fontes e vozes ouvidas para construir essas narrativas e representações.

\section{Metodologia}

Nossa escolha da TV Globo e da TV Record se justifica pela abrangência nacional de seu sinal e pela audiência que elas detêm frente às demais emissoras. Ambas já estão consolidadas e, uma vez que a Record foi criada em $1953^{21}$, é a mais antiga emissora de televisão ainda em atividade no Brasil. Foi comprada pelo bispo da Igreja Universal do Reino de Deus, Edir Macedo, em 1989. Desde então o bispo é o seu maior acionista $^{22}$. É considerada vice-líder de audiência no país e possui 142 veículos de comunicação ${ }^{23}$, é mais assistida pelo público das classes $\mathrm{C}, \mathrm{D}$ e $\mathrm{E}$ do que as demais emissoras ${ }^{24-25}$.

\footnotetext{
i Este estudo integra um projeto mais amplo, apoiado pelo CNPq e pela Faperj, realizado em colaboração com quatro instituições brasileiras (Fundação Oswaldo Cruz, Universidade de São Paulo e Universidade Federal do Pará e de Minas Gerais). Neste artigo, apresentamos um recorte referente aos dados coletados no Rio de Janeiro e relacionados à programação voltada para as ciências da saúde.
} 
A TV Globo, por sua vez, foi criada em 1965. É a maior rede de televisão do Brasil ${ }^{23}$ e, de acordo com as informações oficiais da emissora, sua programação chega a 5.482 municípios e 99,5\% da população

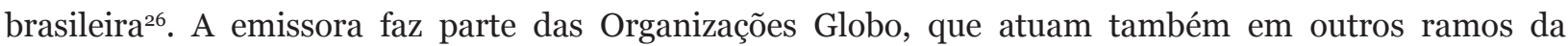
comunicação, como jornais, revistas, emissoras de rádio, TV por assinatura, empresas de distribuição de conteúdo e informação ${ }^{22-23}$.

Para analisar a programação televisiva dessas emissoras, selecionamos uma amostra, constituída por duas semanas construídas totalizando 14 dias, que foi representativa de um período de seis meses do ano de 2013 (junho a novembro). Para compor as semanas construídas, sorteamos aleatoriamente, no período considerado, duas segundas-feiras, duas terças-feiras, duas quartas-feiras, e assim sucessivamente, até termos duas vezes cada dia da semana. Ao todo, foram gravadas 336 horas de cada emissora nas datas mencionadas no Quadro 1 e assistidas na íntegra.

Quadro 1. Datas selecionadas para compor a amostra da pesquisa

\begin{tabular}{|l|l|l|}
\hline Domingo & 22 de setembro & 29 de setembro \\
\hline Segunda-feira & 19 de agosto & 16 de setembro \\
\hline Terça-feira & 18 de junho & 29 de outubro \\
\hline Quarta-feira & 18 de setembro & 13 de novembro \\
\hline Quinta-feira & 12 de setembro & 24 de outubro \\
\hline Sexta-feira & 04 de outubro & 29 de novembro \\
\hline Sábado & 31 de agosto & 14 de setembro \\
\hline
\end{tabular}

Fonte: Elaborada pelos autores

Tal forma de recorte metodológico teve como base o estudo de Whitelegg e colaboradores ${ }^{27}$ e tem respaldo de Silverman ${ }^{28}$, que diz ser essa uma forma aceitável de investigação, principalmente quando se trata de estudo sobre comunicações de massa.

Durante esses dias, gravamos a programação veiculada ao longo de 24 horas pelas referidas emissoras para, posteriormente, assistir e analisar tal material. Ao todo, foram 672 horas gravadas e assistidas. ${ }^{\text {ii }}$ Estabelecemos quatro critérios que seriam necessários para que uma peça fosse incorporada em nosso corpus de análise, tendo como base o protocolo da Rede Ibero-americana de Monitoramento e Capacitação em Jornalismo Científico ${ }^{29}$, associado a Rondelli ${ }^{14}$ e Trench $^{30}$.

Para ser incluída em nosso corpus, a peça precisou satisfazer pelo menos um dos critérios fixados; uma mesma peça podia atender a mais de um critério. Os critérios estabelecidos foram:

- Menção direta à C\&T: citação das palavras ciência, tecnologia, cientistas, pesquisa, pesquisadores, instituições de pesquisa, universidades (desde que relacionadas à produção científica). Menção a métodos ou processos científicos, apresentação de resultados de pesquisas ou produtos desenvolvidos cientificamente, assim como assuntos relacionados à política de C\&T foram incluídos. Também foram incluídas as peças que apresentavam um cientista/pesquisador, desde que identificado dessa maneira.

- Menção a dados e termos científicos: menção a dados ou termos atribuídos à comunidade científica ou a um determinado ramo do conhecimento, mesmo que não sejam proferidos por cientistas. Consideramos como dados científicos informações e/ou reflexões que não podem ser

ii As emissoras possuem programação durante as 24 horas do dia, sem interrupções. 
oriundas do senso comum e, portanto, têm origem no campo científico. Os termos científicos são caracterizados por uma ou um conjunto de palavras que não se encaixam no vocabulário do cotidiano, no senso comum, e são atribuídas à pesquisa científica.

- resença de ilustração e/ou animações relacionadas à ciência: inserção de peças que apresentam algum tipo de ilustração e/ou animação contendo informações científicas ou baseadas nelas, podendo ser uma explicação de um fato, um procedimento científico ou um exemplo da realidade.

- Material de divulgação científica: compreendem as programações televisivas com temáticas científicas voltadas para o público amplo e/ou leigo. Também são consideradas peças de divulgação da ciência aquelas programações que tratam de ações de popularização ou divulgação da ciência, como a Semana de Ciência e Tecnologia, olimpíadas e feiras de ciências, atividades dos museus de ciência, planetários e outros espaços científicos e culturais.

Neste artigo, apresentaremos os resultados referentes às peças televisivas relacionadas às ciências da saúde, tendo como referência a Grande área das Ciências da Saúde de acordo com a classificação do Conselho Nacional para o Desenvolvimento Científico e Tecnológico (CNPq), a saber, temas das áreas de medicina, odontologia, farmácia, enfermagem, nutrição, saúde coletiva, fonoaudiologia, fisioterapia, terapia ocupacional e educação física.

\section{Perfil das ciências da saúde na TV brasileira}

Ao todo, identificamos 1.466 peças que tratavam de assuntos relacionados à ciência de maneira geral, de acordo com os critérios pré-estabelecidos apresentados acima, nas duas emissoras incluídas neste estudo. Dessas, 557 abordaram temáticas das ciências da saúde, sendo 308 da TV Record (55,2\% do total de itens sobre ciências da saúde) e 249 da TV Globo (44,7\%) - e é sobre esse material que recai nossa atenção neste artigo. A duração dessas peças totaliza 8 horas e 18 segundos, o que representa 2,7\% de toda a programação analisada pelo estudo (672 horas).

Como se vê na Figura 1, a grande maioria das peças incluídas no corpus (93,2\%) veiculou menção a termos e dados científicos, em geral por meio do uso da linguagem científica, a exemplo da citação de substâncias químicas, componentes de produtos, nomes científicos de plantas ou animais - nem sempre com explicações sobre esses nomes. Como exemplo ilustrativo de casos recorrentes observados, citamos a propaganda do produto 'Targifor', na qual houve menção a uma substância química que faz parte da composição do produto: "Targifor tem arginina (grifo nosso), que age naturalmente na geração de energia do seu corpo, dando mais disposição pra você fazer o que mais gosta".iii

iii Transcrição de parte da publicidade sobre o produto Targifor, veiculada nas duas emissoras analisadas. 


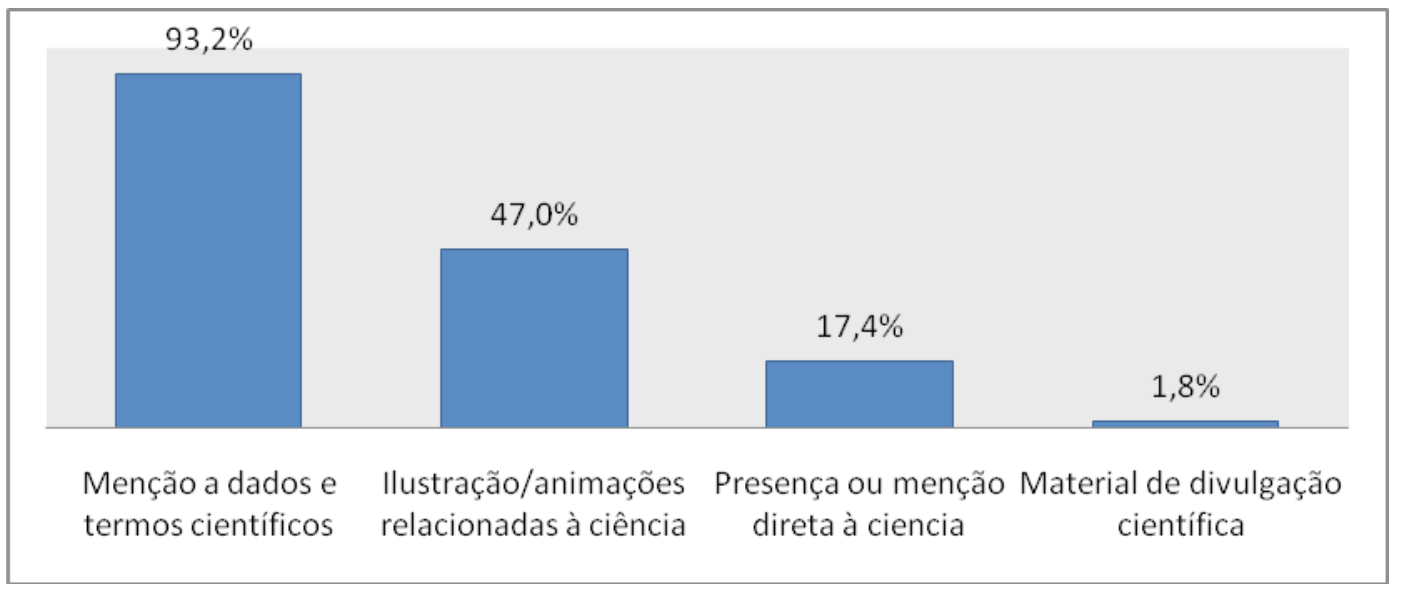

Figura 1. Porcentagem de itens relacionados às ciências da saúde de acordo com os critérios de inclusão no corpusiv Fonte: Elaborada pelos autores

É possível relacionar essa recorrência à menção de termos científicos ao que Kuscinsky ${ }^{31}$ chama de "conflito" entre os profissionais da saúde e da comunicação. Para o autor, os profissionais da saúde possuem restrições quanto à simplificação das informações realizadas pelos comunicadores, pois, para eles, "a linguagem precisa e rigorosa é constitutiva do modo de pensar; não é apenas uma maneira de falar, ela reflete uma maneira de pensar a saúde" ${ }^{31}$. A recorrente presença desses termos, como observamos na programação televisiva analisada, pode estar relacionada, justamente, a essa demanda característica da linguagem da saúde.

Cerca de metade das peças do nosso material $(47,0 \%)$ veiculou ilustrações e animações, entre as quais destacamos as peças de publicidade. A Figura 2 é um exemplo dessas animações que, em geral, representaram o funcionamento do corpo humano ou a reação do organismo aos produtos publicizados. Nesse caso, as imagens abaixo mostram os supostos benefícios do iogurte Yakult a partir de representações animadas do sistema digestivo, produto esse que foi descrito como "o único com probióticos Lactobacillus casei shirota, que contribuem para equilibrar a flora intestinal".

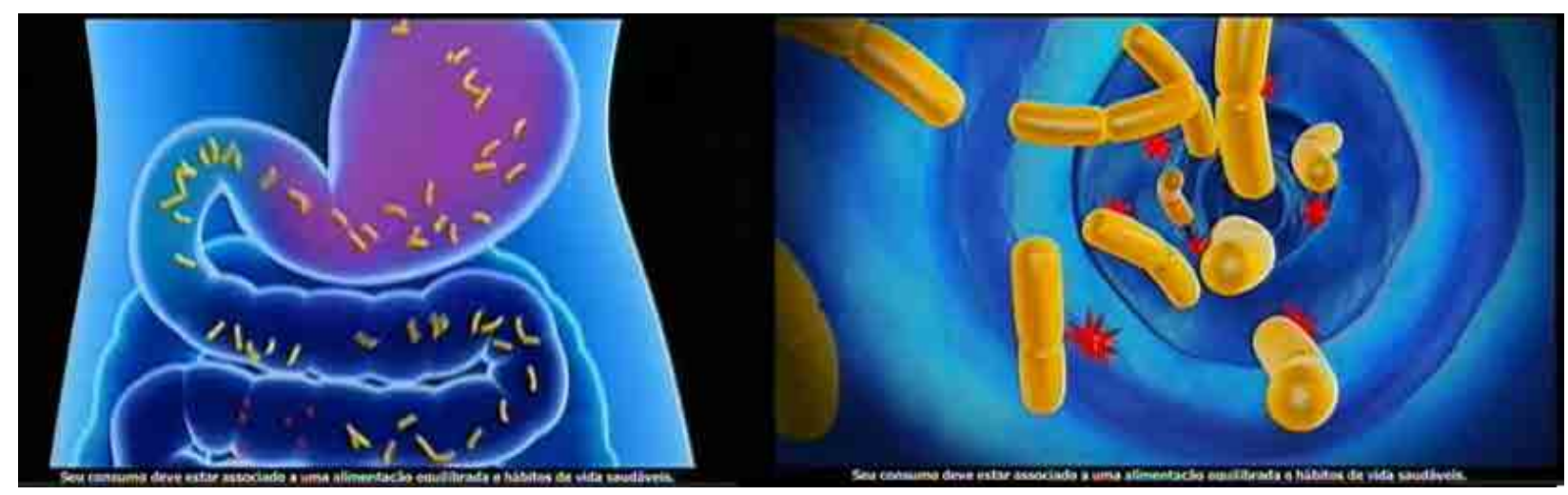

Figura 2. Imagens da propaganda televisiva do iogurte Yakult Fonte: imagem da programação televisiva da TV Globo

Como mostra a Figura 1, menos de um quinto das peças televisivas $(17,4 \%)$ veiculou menção direta às ciências da saúde, a saber, citação das palavras ciência, cientistas, pesquisa, pesquisadores, instituições de pesquisa, universidades (desde que relacionadas à produção científica) ou mencionaram métodos

iv Uma mesma peça poderia ser incluída em mais de um critério, por isso a soma é superior a 100\%.

v Transcrição de parte da publicidade sobre o produto Yakult, veiculada pela TV Globo. 
ou processos científicos, apresentação de resultados de pesquisas ou produtos desenvolvidos cientificamente. A somatória dessas peças chega a 3 horas, 54 minutos e 49 segundos, representando cerca de $0,6 \%$ das horas assistidas.

A presença da figura do cientista nas peças foi ainda menor: apenas 19 das peças, somando 30 minutos e oito segundos ou $0,07 \%$ das horas analisadas neste artigo. A TV Record foi a emissora que apresentou o cientista maior número de vezes, um total de 14 peças que somaram 11 minutos e 15 segundos. Contudo, a TV Globo veiculou peças com maior duração de tempo, já que verificamos apenas cinco perfazendo 18 minutos e 53 segundos.

Considerando todo o corpus, identificamos 19 homens e cinco mulheres cientistas, os quais apresentavam o perfil já consolidado desse profissional: homem, de jaleco branco, trabalhando em seus laboratórios perfil esse que é considerado como o estereótipo "tradicional" de cientista ${ }^{6,17,32-34}$.

A maioria das peças que continham a presença de cientistas eram de publicidade (12 peças das 19 identificadas) que também refletiram esse estereótipo. Nesse caso, lembramos que o jaleco branco é considerado um ícone de vestuário da ciência que está relacionado às práticas profissionais da área da saúde ${ }^{34}$. Vemos alguns exemplos na Figura 3.

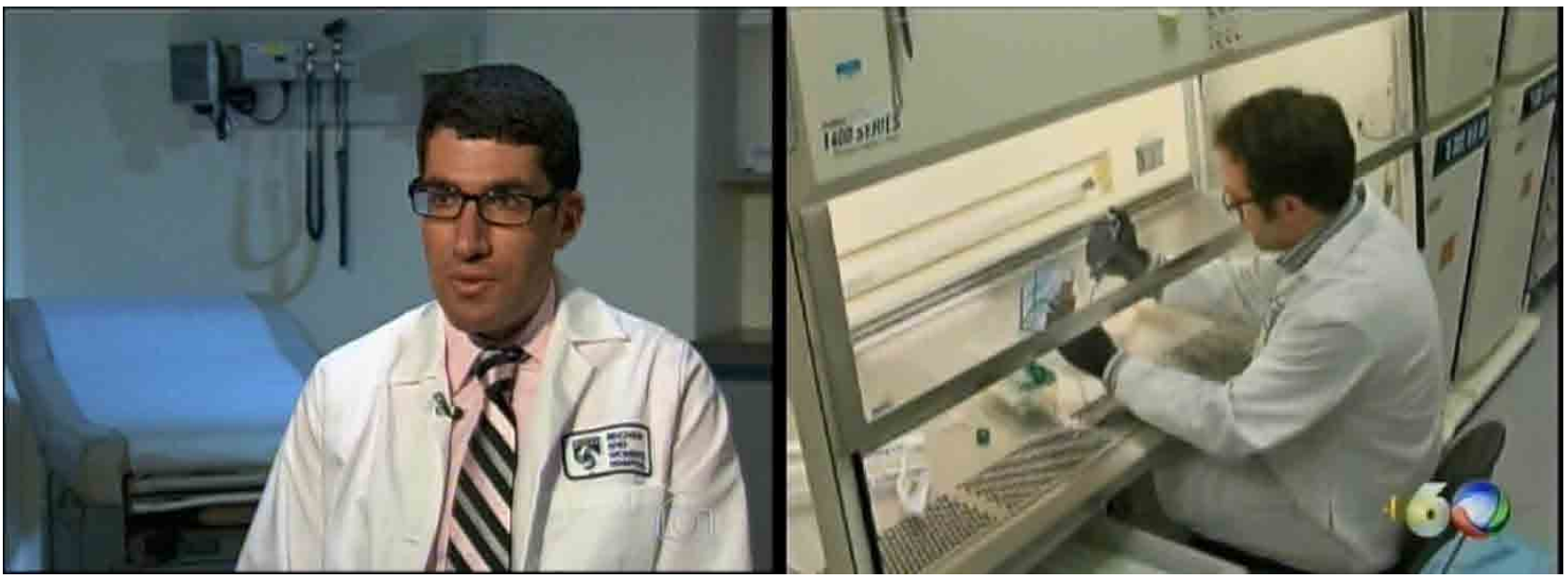

Figura 3. Imagens de programações com a figura do cientista Fonte: Imagens da programação televisiva da TV Globo e TV Record, respectivamente.

As imagens acima exemplificam o perfil do profissional das ciências da saúde encontrado em nosso corpus. À esquerda, uma reportagem, veiculada em 29 de setembro de 2013 no programa Fantástico, da TV Globo, apresentou um cientista norte-americano que desenvolveu uma pesquisa sobre a relação entre o tratamento de diversos tipos de câncer e o estado civil dos pacientes, segundo a qual aqueles que são casados têm vida mais longa que os solteiros. À direita, a reportagem do telejornal Fala Brasil, da TV Record, veiculada em 12 de setembro de 2013, exibiu a imagem de um dos pesquisadores responsáveis pelo desenvolvimento de uma possível vacina contra o HIV.

Os materiais de divulgação científica em nosso corpus foram representados unicamente pelas peças do programa Globo Ciência da TV Globo, criado em 1984 pela Fundação Roberto Marinho (pertencente às Organizações Globo). Considerado pioneiro na divulgação científica na TV brasileira ${ }^{19}$, o programa foi encerrado em agosto de 2014, tendo sido reorganizado em outro formato sob o título de Como será? - que é mais abrangente e aborda outras temáticas, a exemplo de educação e ecologia. 


\section{Categorias televisivas e programas que trabalharam temas das ciências da saúde}

Nosso estudo tomou como a base a categorização apresentada por Aronchi ${ }^{35}$ sobre a programação televisiva brasileira. O autor identifica cinco categorias televisivas em seu estudo: entretenimento, informação, educação, publicidade e outras (programações especiais, religiosas ou eventos).

Em nosso material, verificamos que a publicidade foi a categoria televisiva mais presente quando se trata de assuntos das ciências da saúde, representando 60,9\% do nosso corpus. Nesse caso, é importante destacar que a TV é o maior e o mais importante veículo publicitário do Brasil desde 1980, de acordo com Mattos ${ }^{22}$. Segundo o autor, "os produtos anunciados na televisão tendem a influir nos padrões de consumo" 2 .

Entre as publicidades mais frequentes, destacamos as do hidratante 'Goicoechea' (17,8\%), os produtos odontológicos da Colgate (9,5\%) e os da marca 'Danoninho' (5,7\%). Essas peças têm em comum a menção de dados ou termos científicos e a presença de animações que demonstram uma situação para a qual é dada uma explicação científica.

Também encontramos programações de entretenimento (32,1\%) e informativas (7,0\%), embora não tenhamos identificado peça alguma da categoria televisiva educação que abordasse questões sobre as ciências da saúde.

Em relação às programações de entretenimento, o programa matutino Bem Estar, exibido pela TV Globo de segunda a sexta-feira, discorreu sobre diversos assuntos das ciências da saúde. Voltado para essa temática, o programa traz dois especialistas diariamente para discutir um determinado tema relacionado à saúde e esclarecer dúvidas dos telespectadores. Da mesma forma que a publicidade, o uso de termos científicos e das animações explicando o funcionamento do corpo humano foi bastante recorrente no programa, como exemplificamos na Figura 4.

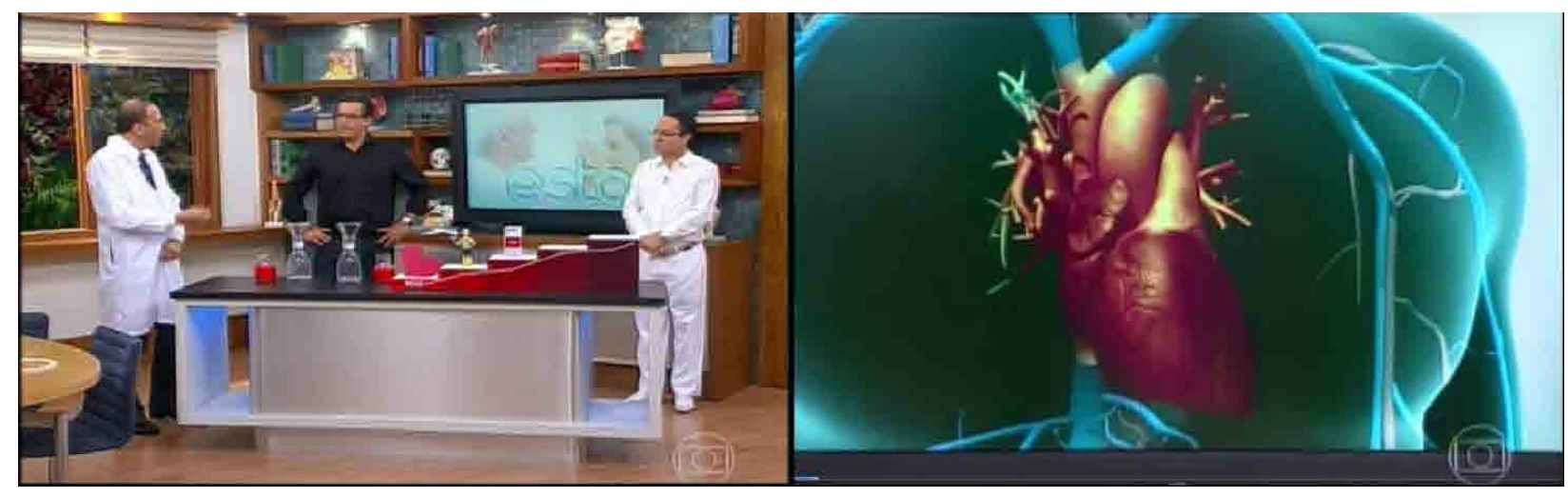

Figura 4. Imagens do programa Bem Estar, exibido pela TV Globo.

Fonte: Imagens da programação televisiva da TV Globo

Na imagem à esquerda, observamos o apresentador ao lado de dois médicos cardiologistas no cenário principal do programa Bem Estar, exibido no dia 18 de junho de 2013. Na imagem à direita, temos uma animação mostrada no telão do próprio cenário do programa que foi explicada por um dos cardiologistas. Durante o programa, os especialistas citaram estudos científicos para embasar algumas de suas explicações.

O programa matutino Hoje em Dia, exibido pela TV Record de segunda a sexta-feira, também apresentou quadros e reportagens relacionados às ciências da saúde. Em especial, ressaltamos o quadro "Você e o doutor", caracterizado pela presença de um médico que apresenta e descreve um problema clínico ou uma doença e responde a perguntas dos apresentadores e convidados. 
Ainda sobre a programação de entretenimento da TV Record, destacamos o Programa da Tarde, vespertino também transmitido de segunda a sexta-feira. O programa apresentou várias peças relacionadas a questões de emagrecimento e controle de peso (2,0\% do corpus), além outras sobre próteses e enfermidades.

Em se tratando de materiais de ficção televisiva, destacaram-se as cenas da novela das $21 \mathrm{~h}$ da TV Globo, Amor à vida, exibida entre maio de 2013 e janeiro de 2014. Um dos cenários principais da telenovela era o ambiente de um hospital e vários dos seus personagens eram médicos, com a presença de cenas em que havia uma discussão sobre questões científicas da medicina, explicações de procedimentos clínicos e de testes laboratoriais, conversas sobre tratamentos de doenças e seus sintomas.

Nesse sentido, lembramos que as telenovelas da TV Globo são reconhecidas nacional e internacionalmente ${ }^{22,27}$ e possuem altos índices de audiência. Algumas delas inclusive já tiveram a ciência como ponto de partida para sua trama central, como foi o caso de O Clone, veiculada na faixa de horário das $20 \mathrm{~h}$ entre os anos de 2001 e 2002. Durante o tempo em que esteve no ar, a telenovela gerou um debate intenso na sociedade sobre assuntos relacionados à clonagem, incluindo questões éticas da ciência. Muito assistida, já foi transmitida em vários outros países e foi foco de pesquisas no país ${ }^{16-17}$, por conta do potencial que teve de aproximar a ciência e a sociedade ao abordar temas científicos em um tipo de programação tão presente na vida dos brasileiros.

O seriado policial norte-americano Crime Scene Investigation (CSI), veiculado de segunda à sextafeira às 21h35 pela TV Record, foi outra programação de ficção que apresentou peças sobre as ciências da saúde, pois sua narrativa se passa em um laboratório de ciência forense. Tal fato propicia a abordagem de assuntos das ciências da saúde a partir de cenas de testes com substâncias químicas, testes de DNA e, principalmente, exames de autópsia da vítima do crime. Ley, Jankowski e Brewer ${ }^{36}$ analisaram episódios do CSI a partir das características atribuídas aos testes de DNA. Segundo os autores, a abordagem dada pelo seriado confere uma alta credibilidade ao teste, por vezes até exacerbada, mas isso pode contribuir para uma melhor compreensão sobre a genética e assuntos das ciências biológicas como um todo.

Quanto às programações informativas, as duas emissoras apresentaram porcentagens similares no que se refere às notícias relacionadas às ciências da saúde incluídas em nossa amostra: TV Globo com 3,6\% e TV Record com 3,4\% do corpus. O telejornal que trouxe mais notícias com esse perfil foi o matutino Fala Brasil, da TV Record, registrando 2,7\% de peças nosso material (15 itens). Podemos ver um exemplo dessas notícias na Figura 5 .

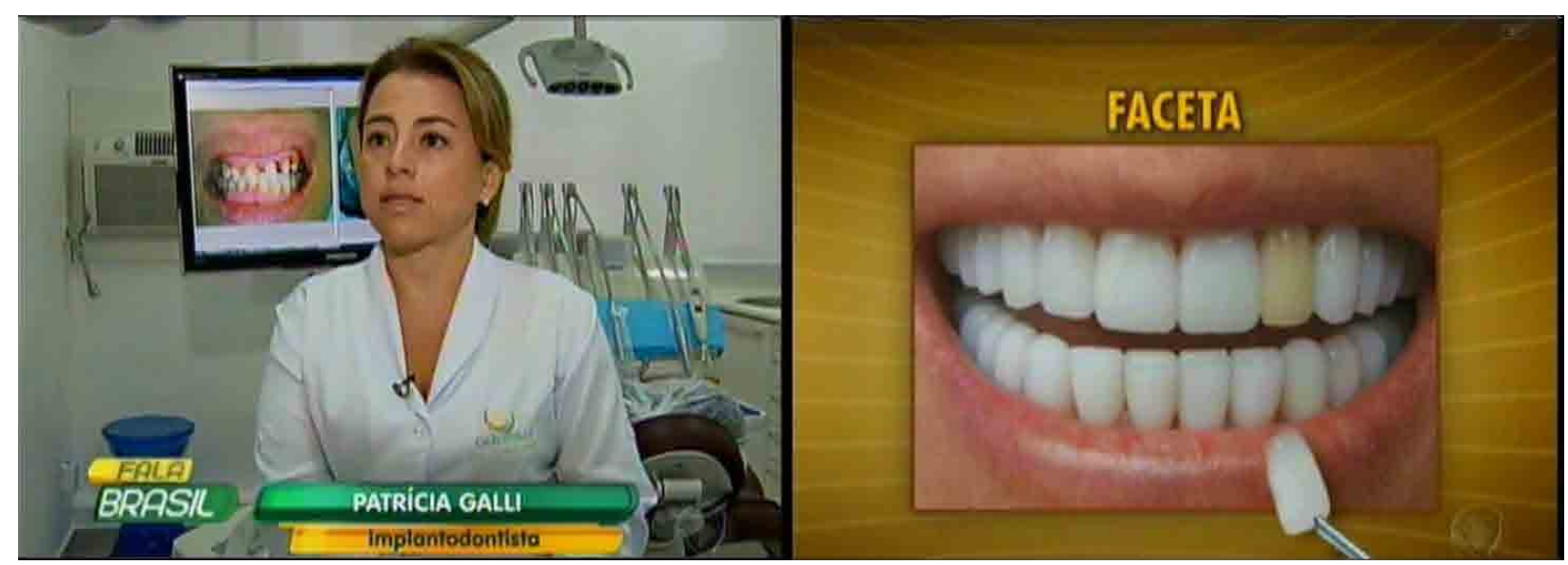

Figura 5. Imagens de reportagem do telejornal Fala Brasil, exibido pela TV Record Fonte: Imagens da programação televisiva da TV Record 
Ela ilustra uma das reportagens veiculadas por aquele telejornal que foram analisadas neste estudo, cujo tema foi um tratamento odontológico do jogador de futebol Ronaldinho Gaúcho. Na reportagem, veiculada em 19 de agosto de 2013, observamos a entrevista com uma dentista especializada em implantes dentários (imagem à esquerda) que explica o procedimento pelo qual o jogador passou para melhorar, esteticamente, o sorriso. As explicações usam alguns termos técnicos da odontologia e imagens ilustrativas (à direita) detalhando o procedimento.

Essa recorrência maior das notícias sobre ciências da saúde no Fala Brasil é um dado interessante, uma vez que as análises sobre a cobertura de ciência pela TV Record têm se debruçado mais sobre o principal telejornal da emissora: o Jornal da Record ${ }^{5,11,37}$. Analisar o telejornal matutino pode ser importante para compreender melhor como a emissora está abordando temas de ciência ao longo de sua programação diária.

A TV Globo, por sua vez, apresentou tais notícias de uma forma distribuída na programação, com as peças em quatro dos cinco telejornais diários da emissora à época. O matutino Bom Dia Brasil foi o que veiculou mais notícias sobre a temática, seguido pelo local Bom Dia Rio e pelo principal telejornal da emissora, o Jornal Nacional. Estudos sobre a cobertura da ciência nesse último - que utilizaram metodologias diversas da apresentada neste artigo e permitem um maior aprofundamento na análise - mostraram a ênfase dada à temática da saúde ${ }^{6,40}$.

\section{Estética e bem-estar: os temas da saúde na TV brasileira}

As temáticas abordadas em nosso material de análise incluíram produtos ou tratamentos estéticos $(20,3 \%$ do corpus), alimentação (18,1\%) e produtos ou assuntos odontológicos (16,3\%). Os itens relacionados aos produtos ou tratamentos estéticos pertencem, basicamente, à categoria televisiva publicidade.

Dodds, Tseëlon e Weitkamp ${ }^{38}$ afirmam que o envolvimento da publicidade com o público é decisivo para a posterior compra do produto, ou seja, quanto mais próxima a relação com o público, maior sua probabilidade de convencimento e posterior consumo. No caso dos cosméticos, esse nível de envolvimento é alto, pois, de acordo com os autores, está ligado a questões de autoestima. Nas propagandas analisadas neste estudo, verificamos esse tipo de discurso marcado pelo reforço à beleza e autoestima - o que ainda foi corroborado pela ciência. Exemplo disso foi a do hidratante Goicoechea, que fez referência a uma melhora na aparência com os dizeres "pernas cientificamente mais belas".

As programações sobre alimentação foram mais variadas no que se refere aos gêneros televisivos, apesar de ainda termos identificado a predominância da publicidade, a exemplo de duas marcas de iogurte: Danoninho (5,7\%) e Activia (4,3\%). No estudo realizado por Torres ${ }^{7}$ sobre propagandas veiculadas na TV da Colômbia, os alimentos também foram o segundo tema mais frequente, superado apenas pela publicidade da indústria farmacêutica. Contudo, também observamos algumas peças de entretenimento e informação sobre o assunto, inclusive tratando de distúrbios alimentares, como anorexia e bulimia.

Além disso, identificamos outro grupo de peças que abordam questões alimentares, porém mais relacionados a assuntos de dieta e controle de peso, que representou 5,7\% do corpus. Os programas da TV Globo, Fantástico (dominical) e Bem Estar, e os da TV Record, Domingo Espetacular (dominical) e Fala Brasil, foram alguns dos que abordaram esse tema em nosso corpus. Esse assunto foi o tema do estudo de Silva e Lerner ${ }^{39}$, ao analisarem um quadro temático do programa Bem Estar que, frequentemente, tratava da questão do emagrecimento. Nesse quadro, houve ênfase em histórias de sofrimento e superação por parte dos telespectadores que apresentavam seus depoimentos ao programa, mostrando o caminho para se chegar ao 'peso ideal' ou 'saudável'. Contudo, de acordo com os autores, a maior motivação para se chegar a esse objetivo era uma questão estética.

Em relação às peças que abordaram questões ou ofertaram produtos odontológicos, verificamos a presença de programações de entretenimento, sobre doenças nas gengivas e distúrbios na mastigação, mas 
ainda houve a predominância de peças de publicidade, principalmente aquelas das marcas Colgate (9,5\%) e Sensodyne (3,4\%).

Ao estudarem a cobertura jornalística sobre a saúde bucal, Cavaca e colaboradores ${ }^{40}$ concluíram que existe uma valorização estética exacerbada quando se fala do tema, fomentando uma demanda utópica para se alcançar um "sorriso perfeito". A ênfase na busca por esse resultado estético 'utópico' também esteve presente nas peças analisadas, principalmente nas propagandas, entre as quais podemos citar a do creme dental Colgate Luminus White que afirma que ele tem "aceleradores de branqueamento, que começam a agir imediatamente para um tom mais branco em uma semana”vi.

Ao analisarem a relação de mulheres com publicidades alimentícias e de cosméticos no Reino Unido, Dodds, Tseëlon e Weitkamp ${ }^{38}$ categorizam produtos cosméticos e alimentícios como produtos de "experiência", ou seja, só é possível saber se tal produto funciona de acordo com o que foi dito na publicidade depois de usá-lo. ${ }^{\text {vii }}$ No caso do nosso estudo, entendemos que os produtos odontológicos também podem ser categorizados dessa forma, de modo que os depoimentos de pessoas que já consumiram produtos de "experiência" e os recomendam têm um valor importante na publicidade - tanto para a construção da narrativa publicitária em si como para o público-alvo daquele produto.

Assuntos mais gerais relacionados à saúde, como o controle do índice de colesterol, tratamentos para alergias, a importância dos exercícios físicos e os problemas em decorrência do uso de drogas e do cigarro, também fizeram parte do nosso material. Ao todo, tais questões representaram 10,0\% de todo o material e estiveram muito relacionadas aos temas trabalhados no programa Bem-Estar.

Programações que enfatizaram remédios estavam em 9,3\% do corpus e dentre elas, novamente, destacam-se as propagandas, a exemplo dos produtos Advil e Tylenol. Os medicamentos foram os produtos que mais se utilizaram do discurso científico na construção de uma narrativa na publicidade analisada por Torres ${ }^{7}$ na Colômbia, o que mostra a importância da indústria farmacêutica no mercado publicitário. Não observamos a mesma predominância desse grupo em nosso estudo, contudo, os remédios ainda representaram quase um décimo das peças identificadas.

As enfermidades foram o assunto de 8,2\% da programação analisada e estiveram presentes em diversas categorias televisivas, nos programas que discorreram sobre doenças como câncer, dengue, diabetes, doenças cardíacas de uma forma geral, Aids, Síndrome de Asperger e de Borderline.

Nossos dados mostram, portanto, a predominância do enfoque estético nas programações relacionadas às ciências da saúde não só nos produtos cosméticos, mas também nos odontológicos, que visam ao "sorriso perfeito" e/ou "super branco", e nas relacionadas à alimentação e ao controle de peso, que buscam pelo corpo "perfeito" e magro, que, muitas vezes, representa o "corpo saudável".

Tal predominância pode ter relação com o que Kuscinsky ${ }^{31}$ chama de elitismo das notícias de saúde, que seria um grande filtro de temáticas entre as quais se valorizam os assuntos de interesse das classes sociais mais altas e do centro econômico do país. O autor afirma que pouco se fala, por exemplo, sobre o surto de hepatite no Amazonas ou sobre doenças como malária, tuberculose ou hanseníase - doenças que não foram encontradas no material analisado pela nossa pesquisa. Kuscinsky ${ }^{31}$ destaca que predominam notícias sobre o corpo e a beleza, exatamente o que observamos em nosso corpus.

vi Transcrição de parte da publicidade sobre o produto Colgate Luminus White, veiculada pelas duas emissoras.

vii A outra categoria descrita pelos autores seria a dos produtos de "busca": bens de consumo duráveis (como equipamentos eletrônicos, carros e computadores) que podem ser avaliados por sua descrição ou publicidade de maneira mais segura que os de "experiência"38. 


\section{Uma imagem positiva das ciências da saúde e as fontes ouvidas}

De maneira geral, encontramos uma ênfase dada às características positivas das ciências da saúde, fato que já tinha sido observado por Chagas e colaboradores ${ }^{41}$ na cobertura sobre as ciências da saúde do Jornal Nacional e do programa Fantástico, ambos da TV Globo. Isso pode ser justificado pelo fato de que mais de $60,0 \%$ das nossas peças eram de publicidade e, portanto, ressaltavam os pontos positivos dos seus produtos, recorrentemente com base em dados científicos - a exemplo dos dizeres característicos das propagandas como o "cientificamente provado" ou "estudos comprovam". Os benefícios da ciência estiveram presentes em 73,1\% das peças, sendo que 82,3\% delas eram publicidade. Já as promessas de benefícios futuros que as ciências da saúde podem trazer ao cidadão foram identificadas em menor quantidade (39,5\%), mas ainda observamos a predominância das peças da categoria televisiva de publicidade ( $95,0 \%$ das peças que apresentaram promessas).

Os temas nos quais essa visão positiva da ciência foi abordada em nosso material são aqueles relacionados a produtos cosméticos e odontológicos, alimentação e remédios. Vários dos produtos já citados - como o hidratante Gocoechea, os produtos da marca Colgate, os iogurtes Activia e Yakult e os remédios Advil e Tylenol - apresentaram tais características positivas, mas também os produtos odontológicos da marca Sensodyne e os cosméticos e remédios da marca Asepxia. Em uma das propagandas da última marca sobre um sabonete antiacne há destaque para o nome de uma substância e a promessa de efeitos rápidos: "[o] exclusivo composto Antiacnil-3, com ingredientes adstringentes, esfoliantes e antissépticos, limpam profundamente e removem o excesso de oleosidade, que ajuda a fechar os poros. Resultados em poucos dias". viii

As controvérsias das ciências da saúde praticamente não estiveram presentes no nosso corpus $(0,5 \%)$ e, quando encontradas, estavam relacionadas a temas de automedicação, depressão e alimentação. No caso da automedicação, a peça se tratava de uma reportagem veiculada no dia 31 de agosto de 2013 pelo Jornal Nacional sobre um mutirão realizado por farmacêuticos com objetivo de tirar várias dúvidas da população em geral. Durante a reportagem, foi apresentado o 'mito popular' segundo o qual se deve ingerir antibióticos com leite. Contudo, tal prática foi considerada errada pelos especialistas - que indicaram outra forma de procedimento. Dessa forma, classificamos a peça como contendo uma controvérsia externa ao campo científico, pois a discussão surgiu do senso comum, de um mito popular - e foi explicado e negado pelos cientistas.

Outra controvérsia encontrada em nosso corpus foi veiculada pelo programa semanal Justus +, da TV Record, no dia 18 de junho de 2013. Nele, há uma entrevista com uma 'blogueira' especializada em temáticas de saúde e controle de peso que foi questionada por nutricionistas sobre as sugestões de dietas publicadas em seu blog. Para os nutricionistas consultados, as informações postadas pela 'blogueira' estavam incorretas.

As principais fontes para as informações apresentadas em nosso material foram de especialistas (75,0\% do corpus), que seriam profissionais com formação no ensino superior - a exemplo de dentistas, enfermeiros, nutricionistas, fonoaudiólogos e fisioterapeutas, entre outros profissionais da saúde - ou aqueles personagens que foram identificados como 'especialistas'. Os médicos $(27,6 \%)$ foram categorizados em um grupo à parte, em razão de sua atuação mais frequente no que refere à abordagem midiática das ciências da saúde - e foram o segundo grupo mais presente. Já os cientistas (11,7\%) estavam em menor número, mas também constituem um grupo importante.

A presença maior dos especialistas em relação aos médicos está relacionada à recorrência dos profissionais da odontologia. Como mencionado anteriormente, uma das publicidades mais frequentes foi de uma marca de produtos odontológicos, de maneira que os dizeres "recomendado pelos dentistas"

viii Transcrição de parte da publicidade sobre o produto da marca Asepxia, veiculada pela TV Record. 
foram usados com bastante frequência, talvez até mais que os mais tradicionais "cientificamente provado" e "estudos comprovam" - construções semânticas recorrentes quando se trata de ciência na TV.

Kuscinsky ${ }^{31}$ destaca o valor que é dado às autoridades da saúde para legitimar uma ideia ou discurso exposto na cobertura jornalística. Mesmo que nosso material não se restrinja a peças jornalísticas, observamos esse padrão de reforço de credibilidade pela utilização dessas fontes, principalmente em publicidade.

Cidadãos foram fonte em pouco mais da metade do nosso corpus (50,6\%). Geralmente, tais personagens apresentavam suas histórias de vida como exemplo de um determinado caso, a superação de uma doença ou o processo de tratamento médico. Dessa forma, podemos dizer que as programações televisivas analisadas não só deram voz às tradicionais fontes da saúde (médicos, cientistas e outros especialistas da área), mas também ouviram a outra ponta do processo: os cidadãos, os pacientes, os consumidores. Torres ${ }^{7}$, analisando publicidades televisivas veiculadas na Colômbia, apresentou dados semelhantes.

\section{Considerações finais}

Neste artigo, apresentamos algumas tendências da programação sobre as ciências da saúde na TV brasileira, a partir da análise das duas emissoras de maior audiência no país. Observamos que temas das ciências da saúde estiveram pouco presentes na programação geral, ocupando apenas 2,7\% das horas assistidas para essa análise. Se considerarmos a referência direta à ciência, sua presença foi ainda mais reduzida, chegando a cerca de $0,6 \%$ de toda a programação analisada. A presença da figura do cientista foi praticamente inexistente, sendo identificada em 0,07\% da programação estudada.

Por outro lado, esses temas surgiram em diferentes gêneros televisivos, como programas de entretenimento, materiais ficcionais e telejornais. Destacam-se programas como o Bem Estar, que apresentou várias discussões relacionadas à temática, levando especialistas e cientistas para discutir tais questões e tirar dúvidas dos telespectadores, a telenovela Amor à vida e o seriado policial CSI, evidenciando que temas de ciência da saúde aparecem em programas dedicados ao lazer, inclusive no horário nobre, com potencial de estimular as conversas familiares e entre amigos sobre tais temas.

Mas foi a publicidade a categoria televisiva que mais se destacou em nosso estudo (60,9\% do corpus), com ênfase em produtos estéticos, alimentícios e odontológicos. Tal categoria contribuiu para a abordagem positiva conferida às ciências da saúde, a partir da menção a seus benefícios e promessas, com rara presença de controvérsias. Essa ênfase na publicidade mostra a necessidade de se estudar, mais profundamente, as propagandas que trabalham com conteúdo científico ou, mais especificamente, baseiam a argumentação na ciência para persuadir os telespectadores a comprarem seus produtos. Estudos como os Pitrelli, Manzoli e Montolli ${ }^{42}$ sobre esse tipo de publicidade na imprensa italiana e de Torres $^{7}$ na TV colombiana podem ser inspirações para pesquisas sobre a realidade brasileira.

No entanto, consideramos que o principal resultado encontrado em nosso estudo foi o uso do discurso científico como legitimador. Na grande maioria das peças incluídas na nossa amostra (93,2\%), verificamos a menção a termos científicos visando agregar valor e conferir credibilidade ao conteúdo trabalhado ou produto publicizado. Em outras palavras, embora as ciências da saúde estivessem pouco presentes na programação, quando elas surgem, aparecem com um status social importante, capazes de legitimar e dar credibilidade às informações televisivas. Este fato se torna ainda mais relevante se considerado que a televisão é o meio de comunicação mais presente nos lares brasileiros e possui grande importância cultural no país. 


\section{Referências}

1. Einsiedel EF. Framing science and technology in the Canadian press. Public underst. sci. 1992;1(1): 9-91.

2. Göpfert W. Scheduled science: TV coverage of science, technology, medicine and social science and programming policies in Britain and Germany. Public underst. sci. 1996;5(4):361-74.

3. León B. Science related information in European television: a study of prime-time news. Publicunderst. sci. 2008;17(4):443-460.

4. Almeida CRM, Buys B, Massarani L. La cobertura de ciencia en América Latina: estudio de periódicos de elite ennueve países de laregión. In: Moreno C, organizadores. Periodismo y divulgación científica: tendencias en el ámbito iberoamericano. Madrid: OEI Biblioteca Nueva; 2011. p. 75-97.

5. Barca LV. Iguarias à hora do jantar: a presença de Ciência e Tecnologia nos telejornais diários. [tese]. Rio de Janeiro: Universidade Federal do Rio de Janeiro; 2004.

6. Ramalho M, Polino C, Massarani L. Do laboratório para o horário nobre: a cobertura de ciência no principal telejornal brasileiro. JCOM. 2012 Jun;11(2):1-10.

7. Torres H. Uso de la ciencia em la publicidad televisiva colombiana: un estudio exploratorio sobre las representaciones de la ciencia em la televison. Universitas humanistica 2013 Jan/Jun; (75):447-75.

8. Bustos-Mora G. Ciencia y tecnologíaenla prensa escrita costarricense: análisis de casos. Rev. Ciencias Sociales 2004; IV(106):215-29.

9. Epstein S. The construction of lay expertise: AIDS activism and the forging of credibility in the reform of clinical trials. Sci Technol Human Values. 1995;20(4):408-37.

10. Brasil. Ministério da Ciência, Tecnologia e Inovação, Centro de Gestão e Estudos Estratégicos, Percepção Pública da C\&T no Brasil [Internet]. Brasília, 2015. [citado 07 jun 2016] Disponível em: http:// pt.slideshare.net/MCTI/percepo-pblica-da-ct-2015-cgee

11. Santos RE, Gomes IMAM. A construção do discurso científico no Jornal Nacional e no Jornal da Record. Anais doXII Congresso de Ciências da Comunicação na Região Nordeste; 2010 jun 10-12; Campina Grande (PB); 2010.

12. Reznik G, Massarani L, Ramalho M, Amorim L. Ciência na televisão pública: uma análise do telejornal Repórter Brasil. Alexandria: R. Educ. Ci. Tecnol. 2014;7(1):157-78.

13. Siqueira D. Ciência na televisão: mito ritual e espetáculo [dissertação]. Rio de Janeiro: Universidade Federal do Rio de Janeiro; 1998.

14. Rondelli, DRR. A ciência no picadeiro: uma análise das reportagens sobre ciência no programa Fantástico [dissertação]. São Paulo: Universidade Metodista de São Paulo; 2004.

15. Medeiros FNS, Massarani, L. A cobertura da gripe A(H1N1) 2009 pelo Fantástico. Intercom: R.bras. Ci.Comun. 2011jan/jun; 34(1):41-59.

16. Massarani L, Moreira I. O clone. Publicunderst. sci. 2002; 11(2):207-8.

17. Guerra R. O discurso sobre a ciência nas telenovelas O Clone e Barriga de Aluguel [dissertação]. Recife: Universidade Federal de Pernambuco; 2004.

18. Guedes, AC. Globo Ciência: inventário e análise do arquivo de cartas recebidas dos telespectadores em 1988 [dissertação]. Rio de Janeiro: Instituto Brasileiro de Informação em Ciência e Tecnologia; Universidade Federal do Rio de Janeiro; 1990.

19. Barca, LV. Ciência e comunicação na TV comercial: 14 anos do programa Globo Ciência. Comum. Educ. 1999 maio/ago;15:81-6.

20. Instituto Brasileiro de Geografia e Estatística. A janela para olhar o país: pesquisa nacional por amostra de domicílios Brasil e síntese de indicadores 2013 [79 slides, color.]. Disponível em: http://www.ibge. gov.br/home/presidencia/noticias/imprensa/ppts/00000018883109232014310419410583.pdf

21. Amorin, ACB. Rede Record: 45 anos de história. São Paulo:Antonio Bellini Editora e Design; 1998.

22. Mattos, S. História da televisão brasileira: uma visão econômica, social e política. 5a ed. Petrópolis: Vozes; 2010.

23. Donos da Mídia [Internet]. Disponívelem: www.donosdamidia.com.br. Acesso em: 26 mar 2016. 
24. Forato, T.Globo e Record têm mais público A/B: SBT ganha entre os jovens: Record também tem público mais velho entre as três maiores emissoras do país, aponta lbope em pesquisa de junho [Internet]. São Paulo: Na Telinha; 2015 jul 22. [citado 1 set 2015] Disponível em: http://natelinha.uol. com.br/noticias/2015/07/22/globo-e-record-tem-mais-publico-ab-sbt-ganha-entre-os-jovens-90952.php

25. Raizer F.Globo e Record temmais publico A/B, SBT vence entre os jovens. Conexão TV: a tv emprimeiro lugar. 2015 jul 22. [9 nov 2015] Disponível em: https://conexaotvaudiencia.wordpress.com/2015/07/22/ globo-e-record-tem-mais-publico-ab-sbt-vence-entre-os-jovens/

26. NEGÓCIOS GLOBO. Atlas de cobertura. Disponível em: http://comercial2.redeglobo.com.br/ atlasdecobertura/Paginas/Totalizador.aspx. Acesso em 07 jun 2016.

27. Whitelegg E, Holliman R, Carr J, Scanlon E, Hodgson B. (In)visiblewitnesses: investigating gendered representations of scientists, technologists, engineers and mathematicians on UK children's television. Bradford:UK Resource Centre for Women in Science, Engineering and Technology; 2008.

28. Silverman D. Interpreting Qualitative data: methods for analysing talk, text and interaction. London: SagePublications; 1993.

29. Massarani L. Ramalho M, organizadores. Monitoramento e capacitação em jornalismo científico: a experiência de uma rede ibero-americana. Rio de Janeiro: Museu da Vida, Casa de Oswaldo Cruz, Fiocruz, Centro Internacional de Estudios Superiores de Comunicación para América Latina; 2012.

30. Trench B. Media studies module. The European Network of Science Communication Teachers; 2003. [citado 07 jun 2016] Disponível em: www.polsoz.fu-berlin.de/kommwiss/arbeitstellen/ wissenskommunikation/media/media studies_commentary.doc

31. Kucinski B. Jornalismo e saúde na era neoliberal. Saudesoc. 2002;11(1):95-103.

32. Mead M, Metraux R. Image of the scientist among high-school students: a pilot study. Science. 1957;30(126):384-90.

33. Rosa MIP, LudwigBE, WirthIG, FrancoPC, DuarteTF. Os cientistas nos desenhos animados e os olhares das crianças. In: Borges RNO, organizador.Atas do V Encontro Nacional de Pesquisa em Educação em Ciências; Bauru (SP); 25-29 de novembro de 2005.

34. Long M, Steinke J, Applegate B, Lapinski MK, Johnson M, Ghosh S. Portrayals of male and female scientists in television programs popular among middle school-age children. Science Commun. 2010;20(10):1-27.

35. Aronchi JC. Gêneros e formatos na televisão brasileira. São Paulo: Summus; 2004.

36. Ley BL, Jankowski N, Brewer P. Investigating CSI: portrayals of DNA testing on a forensic crime show and their potential effects. Public Underst Sci. 2012 Jan;21(1):51-67.

37. Alberguini A. A ciência nos telejornais brasileiros: o papel educativo e a compreensão pública das matérias de C\&T[tese]. São Paulo: Universidade Metodista de São Paulo; 2007.

38. Dodds R, Tseëlon E, Weitkamp E. Making sense scientific claims in advertising. A study of scientifically aware consumers.Public Underst Sci. 2008 Apr;17(2):211-30.

39. Silva TRN, Lerner K. Emagrecimento como passaporte para uma nova (e feliz) identidade: vc no Bem Estar e as narrativas biográficas de sofrimento e superação. In: XII CongresoLatinoamericano de Investigadores de la Comunicación; 2014 agosto 6-8; Lima (Peru): ALAIC, PUCP; 2014. [citado 07 jun 2016] Disponível em: http://congreso.pucp.edu.pe/alaic2014/wp-content/uploads/2013/09/ T\%C3\%A3nia-Neves.pdf

40. Cavaca AG, Gentilli V, Marcolino EM, Emmerich A. Representations of oral health in the printed media. Interface(Botucatu). 2012 out./dez.;16(43):1055-68.

41. Chagas C, Massarani L, Reznik G, Ramalho M. Investigação em medicina e saúde no horário nobre: análise de dois programas televisivos brasileiros. Razón y Palabra. 2013 marzo/maio;82:1-21.

42. Pitrelli N, Manzoli F, Montolli B. Science in advertising: uses and consumptions in the Italian press. Public Underst Sci. 2006;15(2):207-20. 